\title{
Better prioritization to increase research value and decrease waste
}

\author{
Agnes Dechartres ${ }^{1,2,3,4^{*}}$ and Philippe Ravaud ${ }^{1,2,3,4,5}$
}

\begin{abstract}
In a recent study published in BMC Medicine, Singh Ospina and colleagues outlined the important gaps between ongoing research and research needs in the field of endocrinology. Many recommendations from clinical practice guidelines are based on a low level of evidence, thereby resulting in research gaps. Despite the publication of around 25,000 randomized controlled trials each year, ongoing research does not cover most of these gaps. In contrast, trials are planned when sufficient data are already available for decision making, which results in redundant research and exposes patients to unnecessary risks. This lack of prioritization contributes to the enormous problem of waste in research. A systematic approach to accumulate the available body of evidence is necessary to determine when we have sufficient evidence and when we have knowledge gaps, defined as research questions with no or a low level of evidence available. Systematic registration of research gaps and their prioritization may help to organize future research. Some initiatives exist, but they need to be generalized.
\end{abstract}

Please see related research: http://www.biomedcentral.com/1741-7015/13/187

Keywords: Randomized controlled trials, Knowledge gaps, Planning, Research agenda, Waste

\section{Background}

Waste related to poor planning and prioritization of research

In 2009, Chalmers and Glasziou highlighted the enormous problem of waste in research, estimating that up to $85 \%$ of research investment is wasted [1]. Waste occurs at all stages of research [2-7] and particularly affects planning and prioritization. We have increasing evidence that many trials address low-priority questions that are poorly related to the burden of disease [8] and patient or physician needs $[9,10]$, do not address patient-important outcomes [11] or use an inadequate comparator. For example, in rheumatology, few trials compare biologically active drugs against each other; comparisons against placebo represent $80 \%$ of trials registered at ClinicalTrials.gov [12]. This lack of head-tohead trials does not allow for answering the pragmatic question raised by patients and their physicians: for this

\footnotetext{
* Correspondence: agnes.dechartres@htd.aphp.fr

${ }^{1}$ Centre de Recherche Epidémiologie et Statistique, INSERM U1153, Paris, France

${ }^{2}$ Centre d'Epidémiologie Clinique, Hôpital Hôtel-Dieu, Assistance

Publique-Hôpitaux de Paris, 1 place du Parvis Notre Dame, 75004 Paris,

France

Full list of author information is available at the end of the article
}

particular disease, which treatment is most effective? Also, it exposes patients to unnecessary risks [12, 13]. Last but not least, trials are frequently planned regardless of the existing evidence. More than $50 \%$ of trial protocols do not refer to systematic reviews [14]. Many trials are planned when sufficient data are already available for decision making, which results in redundant research and exposes patients to unnecessary risks [3]. In contrast, trials are not planned when they are needed to fill research gaps, as highlighted by Singh Ospina and colleagues in a recent study published in BMC Medicine [15]. The authors defined research gaps as clinical questions with a very low level of evidence according to the Grading of Recommendations Assessment, Development and Evaluation (GRADE) approach from clinical practice guidelines [15].

\section{The worrying proportion of clinical practice guidelines} based on a poor level of evidence

In many clinical practice guidelines, few of the recommendations are based on high-level evidence [16-18]. For example, a 2009 study published in JAMA showed that $11 \%$ of the recommendations in clinical practice guidelines from the American College of Cardiology 
(ACC) and the American Heart Association (AHA) were considered to be based on a high level of evidence [18]. Identifying clinical questions for which only low-level evidence is available should, in theory, help in planning future clinical trials focusing on these areas. Nevertheless, a study evaluating practice guidelines from the Infectious Diseases Society of America showed no improvement in proportion of recommendations with a high level of evidence over time [17]. It is very worrying that, despite the publication of around 25,000 randomized controlled trials each year, clinical practice guidelines continue to rely mostly on a poor level of evidence, with potentially serious consequences for patient care [19]. Singh Ospina and colleagues used ClinicalTrials.gov to assess the response in terms of new, active studies conducted for research questions with a very low quality of evidence according to the Endocrine Society clinical practice guidelines [15]. The authors found active studies for only one of five recommendations, which suggests that ongoing research does not sufficiently adapt to fill knowledge gaps in endocrinology.

\section{Identifying gaps to decrease waste}

The research community is becoming increasingly concerned by these issues. We need to add incremental value to existing evidence by a better connection to future research. A first step is to systematically identify research gaps. As outlined by Singh Ospina and colleagues, clinical practice guidelines could be helpful. In the same way, systematic reviews, by synthesizing the available body of evidence, have a key role to play. The Cochrane Collaboration clearly recommends that review authors systematically comment on the need for further research in a separate section of the review, called "Implications for research" [20]. Then, a second step would be to record research gaps. Some initiatives already exist. The UK Database of Uncertainties about the Effects of Treatments (UK DUETs), established by the National Institute for Health and Care Excellence (NICE), publishes treatment uncertainties reported by patients and clinicians and derived from research recommendations and systematic reviews [21]. The Agency for Health Research and Quality (AHRQ) has developed an approach to identify and prioritize future research needs to be used by researchers and funders to help improve the body of comparative effectiveness evidence that would be useful for decision makers [22]. However, there is not enough information about these burgeoning initiatives. Nothing is done to facilitate the registration of research gaps from different resources and there is no particular incentive for review authors and those of clinical practice guidelines to do so. A joint initiative to centralize registration of gaps in a simple and comprehensible way would be very helpful to enhance communication between researchers, physicians and funders. Finally, the response in terms of new active studies conducted should be monitored to assess the adequacy between ongoing research and knowledge gaps. With the requirement to register trials at ClinicalTrials.gov or in other registries, assessing the clinical trial enterprise and monitoring whether ongoing research fits with research needs has become easier.

\section{Conclusions}

Better prioritization of future research is necessary to increase research value in a context of limited human and monetary resources. Some initiatives exist to register and prioritize research gaps. Such efforts should be encouraged and generalized to realign future studies with the existing body of evidence.

\section{Abbreviations}

ACC: American College of Cardiology; AHA: American Heart Association; AHRQ: Agency for Health Research and Quality; NICE: National Institute for Health and Care Excellence; UK DUETs: UK Database of Uncertainties about the Effects of Treatments.

\section{Competing interests}

The authors declare that they have no competing interests.

\section{Authors' contributions}

$A D$ and PR wrote the commentary. Both authors read and approved the final manuscript.

\section{Author details}

${ }^{1}$ Centre de Recherche Epidémiologie et Statistique, INSERM U1153, Paris, France. ${ }^{2}$ Centre d'Epidémiologie Clinique, Hôpital Hôtel-Dieu, Assistance Publique-Hôpitaux de Paris, 1 place du Parvis Notre Dame, 75004 Paris, France. ${ }^{3}$ Faculté de Médecine, Université Paris Descartes, Sorbonne Paris Cité, Paris, France. ${ }^{4}$ French Cochrane Centre, Paris, France. ${ }^{5}$ Department of Epidemiology, Mailman School of Public Health, Columbia University, New York, NY, USA.

Received: 10 September 2015 Accepted: 17 September 2015

Published online: 29 September 2015

\section{References}

1. Chalmers I, Glasziou P. Avoidable waste in the production and reporting of research evidence. Lancet. 2009:374:86-9.

2. Al-Shahi Salman R, Beller E, Kagan J, Hemminki E, Phillips RS, Savulescu J, et al. Increasing value and reducing waste in biomedical research regulation and management. Lancet. 2014;383:176-85.

3. Chalmers I, Bracken MB, Djulbegovic B, Garattini S, Grant J, Gulmezoglu AM, et al. How to increase value and reduce waste when research priorities are set. Lancet. 2014;383:156-65.

4. Chan AW, Song F, Vickers A, Jefferson T, Dickersin K, Gotzsche PC, et al. Increasing value and reducing waste: addressing inaccessible research. Lancet. 2014;383:257-66.

5. Glasziou P, Altman DG, Bossuyt P, Boutron I, Clarke M, Julious S, et al. Reducing waste from incomplete or unusable reports of biomedical research. Lancet. 2014;383:267-76.

6. loannidis JP, Greenland S, Hlatky MA, Khoury MJ, Macleod MR, Moher D, et al. Increasing value and reducing waste in research design, conduct, and analysis. Lancet. 2014;383:166-75.

7. Macleod MR, Michie S, Roberts I, Dirnagl U, Chalmers I, loannidis JP, et al. Biomedical research: increasing value, reducing waste. Lancet. 2014;383:101-4

8. Emdin CA, Odutayo A, Hsiao AJ, Shakir M, Hopewell S, Rahimi K, et al. Association between randomised trial evidence and global burden of 
disease: cross sectional study (Epidemiological Study of Randomized Trials-ESORT). BMJ. 2015;350:h117.

9. Corner J, Wright D, Hopkinson J, Gunaratnam Y, McDonald JW, Foster C. The research priorities of patients attending UK cancer treatment centres: findings from a modified nominal group study. Br J Cancer. 2007;96:875-81.

10. Tallon D, Chard J, Dieppe P. Relation between agendas of the research community and the research consumer. Lancet. 2000;355:2037-40.

11. Gandhi GY, Murad MH, Fujiyoshi A, Mullan RJ, Flynn DN, Elamin MB, et al. Patient-important outcomes in registered diabetes trials. JAMA. 2008;299:2543-9.

12. Estellat C, Ravaud P. Lack of head-to-head trials and fair control arms: randomized controlled trials of biologic treatment for rheumatoid arthritis. Arch Intern Med. 2012;172:237-44.

13. Ioannidis JP, Karassa FB, Druyts E, Thorlund K, Mills EJ. Biologic agents in rheumatology: unmet issues after 200 trials and $\$ 200$ billion sales. Nat Rev Rheumatol. 2013;9:665-73.

14. Jones AP, Conroy E, Williamson PR, Clarke M, Gamble C. The use of systematic reviews in the planning, design and conduct of randomised trials: a retrospective cohort of NIHR HTA funded trials. BMC Med Res Methodol. 2013;13:50.

15. Singh Ospina N, Rodriguez-Gutierrez R, Brito JP, Young Jr WF, Montori VM. Is the endocrine research pipeline broken? A systematic evaluation of the Endocrine Society clinical practice guidelines and trial registration. BMC Med. 2015:13:187.

16. Hazlehurst JM, Armstrong MJ, Sherlock M, Rowe IA, O'Reilly MW, Franklyn JA, et al. A comparative quality assessment of evidence-based clinical guidelines in endocrinology. Clin Endocrinol (Oxf). 2013;78:183-90.

17. Lee DH, Vielemeyer O. Analysis of overall level of evidence behind Infectious Diseases Society of America practice guidelines. Arch Intern Med. 2011;171:18-22.

18. Tricoci P, Allen JM, Kramer JM, Califf RM, Smith Jr SC. Scientific evidence underlying the ACC/AHA clinical practice guidelines. JAMA. 2009;301:831-41.

19. Heath I. Who's complacent now? The King's Fund on general practice. BMJ. 2011;342:d2254.

20. Higgins JPT, Green S. Cochrane handbook for systematic reviews of interventions. Version 5.1.0 (updated March 2011). Oxford: The Cochrane Collaboration; 2011. Accessed 23 Sept 2015. http://www.cochranehandbook.org.

21. UK Database of Uncertainties about the Effects of Treatments (UK DUETs). Accessed 23 Sept 2015. http://www.library.nhs.uk/duets/

22. Chang SM, Carey TS, Kato EU, Guise JM, Sanders GD. Identifying research needs for improving health care. Ann Intern Med. 2012;157:439-45.

\section{Submit your next manuscript to BioMed Central and take full advantage of:}

- Convenient online submission

- Thorough peer review

- No space constraints or color figure charges

- Immediate publication on acceptance

- Inclusion in PubMed, CAS, Scopus and Google Scholar

- Research which is freely available for redistribution 